\title{
Moderate Hemophilia B Diagnosed by Massive Gastro- intestinal Hemorrhage on the First Day of Life: A Case Report and Literature Review
}

Sook-Hyun Park, M.D., and Byung-Ho Choe, M.D.

Department of Pediatrics, Kyungpook National University School of Medicine, Daegu, Korea

\section{ABSTRACT}

Gastrointestinal hemorrhage in neonates is commonly associated with necrotizing enterocolitis, cow's milk protein allergy, and gastrointestinal malformation. Gastrointestinal bleeding on the first day of life, presenting as the first manifestation of a disorder, has rarely been reported associations with gastric ulceration, Salmonella infection, and allergic colitis. Hemophilia B is also a rare cause of gastrointestinal bleeding during the neonatal period. In the present case, a male infant developed repetitive hematemesis on the first day of life. His initial level of coagulation factor IX was $1.9 \%$, and he was diagnosed with moderate hemophilia B. No further hematemesis or melena was observed during recombinant factor IX therapy. The infant did not have a family history of hemophilia. In conclusion, although gastrointestinal hemorrhage on the first day of life as the first manifestation of a disease is rare, infants who present with spontaneous gastrointestinal hemorrhage after birth and with unexplained prolonged activated partial thromboplastin time should be evaluated for coagulation factor deficiency regardless of whether they have any family history of hemophilia.

Key Words: Gastrointestinal hemorrhage, Hemophilia B, Newborn

\section{INTRODUCTION}

Gastrointestinal hemorrhage $(\mathrm{GIH})$ in neonates is commonly associated with necrotizing enterocolitis (NEC), cow's milk allergy, and gastrointestinal (GI) malformation ${ }^{1,2)}$. GIH on the first day of life as the first symptom of a specific disease has rarely been reported, which were associated with gastric ulceration, Salmonella infection, and allergic colitis ${ }^{3-5)}$. Hemophilia B is an X-linked recessive disorder due to a deficiency of plasma coagulation factor IX, and it affects 0.25 per 10,000 males ${ }^{1)}$. The first bleeding episode of hemophilia B in newborns has been reported to be commonly associated with blood sampling, intracranial hemorrhage (ICH), and extracranial hemorrhage (ECH) after delivery using a vacuum or forceps, umbilical cord clamping, and circumcision ${ }^{6,7)}$. Although previous studies have
Received: 15 August 2016

Revised: 7 October 2016

Accepted: 11 October 2016

Correspondence to: Sook-Hyun Park Department of Pediatrics, Kyungpook National University School of Medicine, 130 Dongdeokro, Jung-gu, Daegu 41944, Korea Tel: +82-53-420-5704 Fax: +82-53-425-6683 E-mail: park_sh@knu.ac.kr

Copyright(c)

By Korean Society of Neonatology. All right reserved.

This is an Open-Access article distributed under the terms of the Creative Commons Attribution Non-Commercial License (http://creativecommons.org/licenses/ by-nc/4.0), which permits unrestricted non-commercial use, distribution, and reproduction in any medium, provided the original work is properly cited. 
reported GIH as the first clinical manifestation of hemophilia B in neonates ${ }^{1,8)}$, GIH occurring on the first day of life has not yet been reported. Here, we report a case of massive spontaneous GIH that occurred on the first day of life, caused by moderate deficiency of plasma coagulation factor IX.

\section{CASE REPORT}

A male infant presented with repetitive hematemesis on the first day of life. He was born by cesarean section at a gestational age of 38 weeks and 3 days to a 29-year-old nullipara. His Apgar scores were 8 at $1 \mathrm{~min}$ and 9 at $5 \mathrm{~min}$. His birth weight was 3,240 $\mathrm{g}$ and head circumference was $34 \mathrm{~cm}$. He had no family history of hemophilia or bleeding tendency. His mother had no history of taking any medicines during pregnancy. He was intramuscularly administered $1 \mathrm{mg}$ of vitamin K shortly after delivery.

The infant was fed sugar water and formula milk first, after which he vomited; the vomitus and gastric content from gastric lavage consisted of fresh blood. Apt test revealed that the blood originated from the neonate. His initial complete blood count was as follows: hemoglobin, $14.5 \mathrm{~g} / \mathrm{dL}$; hematocrit, $44 \%$; and platelet count, $325 \times 10^{9} / \mu \mathrm{L}$. On admission to neonatal intensive unit, the infant developed massive hematochezia and melena. He seemed pale and his heart rate was 175 beats per minute. The levels of hemoglobin and hematocrit at the 6-hour follow-up dropped to $7.7 \mathrm{~g} / \mathrm{dL}$ and $22 \%$, respectively. Massive GIH persisted during erythrocyte transfusion, and the infant required continuous transfusion to compensate for the blood loss. Coagulation tests were performed before infusion of fresh frozen plasma (FFP) transfusion and factor replacement, which showed prothrombin time of 14.1 (reference range, 10.1-15.9) seconds and activated partial thromboplastin time (aPTT) of 132.8 (reference range, 31.3-54.3) seconds. The levels of d-Dimer, fibrinogen, and antithrombin III were $0.8 \mu \mathrm{g} / \mathrm{mL}$ (reference range, $0-1.0 \mu \mathrm{g} / \mathrm{mL}$ d-Dimer units), 174.8 (reference range, 167$399 \mathrm{mg} / \mathrm{dL}$ ), and 52\% (reference range, 39-87\%), respectively. The liver enzyme level was normal. The infant was administered FFP and his coagulation factor levels were measured to evaluate the cause of prolonged aPTT. The initial level of factor IX was $1.9 \%$ (reference range, 15-91\%). The concentrations of other coagulation factors including factor VII, VIII, X, XI, and XII were entirely within the normal range. The infant was diagnosed with moderate hemophilia B, after which factor IX replacement was started.

The levels of factor IX increased by $23.6 \%$ after the first recombinant factor IX replacement (facnyne ${ }^{\circledR}, 100 \mathrm{IU} / \mathrm{kg}$ ) as a treatment for life-threatening hemorrhage. The aPTT was corrected by 38.1 seconds. The massive GI bleeding was controlled, after which half the dose of the first recombinant factor IX (50 IU/kg) was infused for 7 days by measuring the serial concentrations of factor IX. The levels of factor IX were maintained at approximately 2-3\%. Upper GI endoscopy on the first day of life demonstrated diffuse hyperemic gastric mucosa with oozing fundus, without esophageal involvement (Figure 1). Gastric mucosal biopsy was not performed during endoscopy because of the severe bleeding tendency of the infant. Physical examination showed no signs of cephalohematoma or subgaleal hemorrhage. Brain ultrasonography revealed no evidence of intracranial hemorrhage, and abdominal X-radiography and

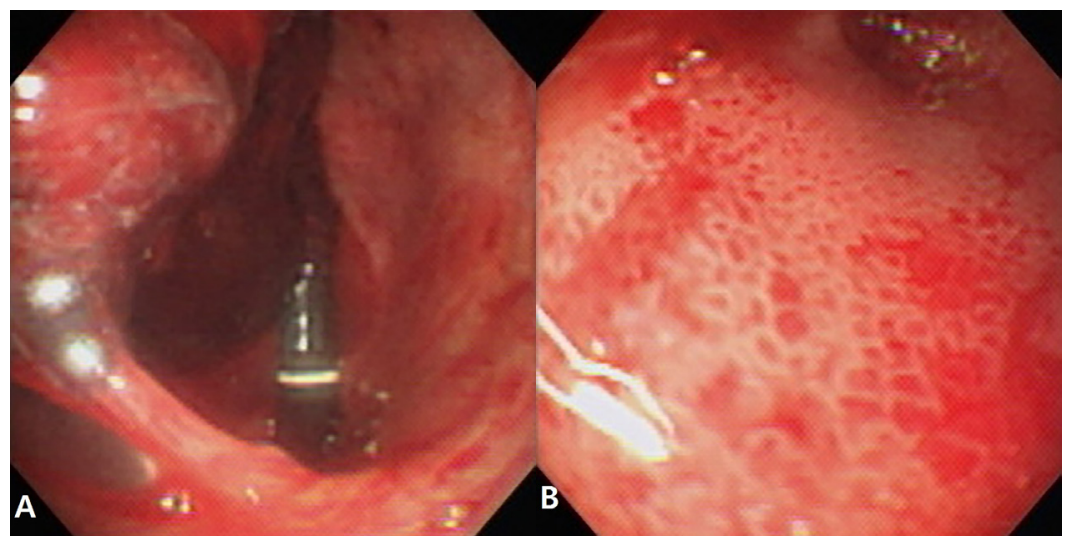

Figure 1. Upper gastrointestinal endoscopy revealed (A) a huge blood clot in the stomach, diffuse hyperemia, and purpuric mucosa and telangiectasia at the fundus and (B) multiple petechiae in the gastric body. 
ultrasonography showed neither a definite intestinal anomaly nor any evidence of necrotizing enterocolitis. No further hematemesis or melena developed during recombinant factor IX therapy. Enteral feeding with breast milk was started, and no symptoms of re-bleeding were observed. A prophylactic dose (25 IU/kg) was infused, and the levels of factor IX were between $2 \%$ and $3 \%$. The infant received prophylactic therapy and was exclusively fed breast milk for 6 months. The levels of factor IX were maintained at about 3\%, however, he did not show any spontaneous bleeding. A reassessment of the family history of the infant revealed no relatives with hemophilia or bleeding tendency.

\section{DISCUSSION}

GIH during the neonatal period is commonly associated with swallowing of maternal blood; maternal use of medicines such as phenytoin, phenobarbital, aspirin, and warfarin; and even cow's milk allergy, NEC, and GI anomaly $^{1,2,9)}$. GIH on the first day of life, presenting as the first manifestation of any disorder, has been rarely reported, and it was associated with gastric ulceration, Salmonella infection, and allergic colitis (Table 1). GIH presented massive hematemesis from gastric ulcers and hematochezia by Salmonella infection and allergic colitis. These infants showed normal coagulation test results. In case of infants with allergic colitis, histopathological findings of colonic mucosa revealed diffuse eosinophilic infiltration in the lamina propria ${ }^{4}$. In the present case, the infant did not have any symptoms after the initial sugar water feed, however, GIH developed after one feed of formula milk. This could be attributed to an allergic reaction, however, a biopsy was not performed because upper GI endoscopy was limited owing to the severe bleeding tendency of the infant.

Although 15-33\% of the infants with inherited coagulopathy are diagnosed with hemorrhagic episodes during the neonatal $\operatorname{period}^{10)}$, the most common initial bleeding manifestations are associated with circumcision and delivery, presenting as ICH and $\mathrm{ECH}^{7)}$. Spontaneous bleeding as the first manifestation of hemophilia during the neonatal period has rarely been reported ${ }^{11)}$. This relatively lower risk of spontaneous bleeding in newborns with hemophilia suggests that hemostasis during the neonatal period may be associated with a tendency of thrombosis rather than hemorrhage ${ }^{6)}$. Hemophilia B is an X-linked recessive coagulopathy with a prevalence of 0.99 per 100,000 males in Korea ${ }^{12)}$. Early attention to a family history of hemophilia, carrier status, and hemorrhagic symptoms have contributed to earlier diagnosis of this condition; however, approximately $30-50 \%$ of newly diagnosed patients show sporadic development of hemophilia $\mathrm{B}^{2,13)}$. Previous studies have reported spontaneous GI bleeding during the neonatal period as the first clinical manifestation of hemophilia (Table 1$)^{1,2,8,11,14)}$. The severity of hemophilia was classified as follows: mild (factor activity 6-30\%), moderate (factor activity 1-5\%), and severe (factor activity $<1 \%$ ) ${ }^{15)}$. The severity, increased aPTT, age of onset, and the type of hemophilia in these cases varied. Half of the patients had no family history of hemophilia.

Mucosal bleedings such as GIH and epistaxis are more common in von Willebrand disease, and in factor X and factor XIII deficiency than in hemophilia A or $\mathrm{B}^{2)}$. Hemophilia is commonly diagnosed by bleeding events that accompany iatrogenic procedures including delivery, cord clamping, blood sampling, circumcision, and trauma after the beginning of crawling or walking during infancy ${ }^{11)}$. Mucosal bleeding rarely develops in newborns with hemophilia; further, mild to moderate hemophilia is rarely associated with spontaneous bleeding. In a previously reported case, GIH in mild hemophilia A was accompanied by duodenal vessel malformation ${ }^{2}$. In the present case, the possibility of cow's milk protein allergy was considered, and the infant was fed only breast milk after control of the GIH

Table 1. Reported Cases of Gastrointestinal Hemorrhage in the First Day of Life

\begin{tabular}{|c|c|c|c|c|}
\hline Authors & $\begin{array}{c}\text { Age at } \\
\text { presentation (h) }\end{array}$ & $\begin{array}{c}\text { Manifestation } \\
\text { of GIH }\end{array}$ & Diagnosis & Upper GI endoscopic/Colonoscopic findings \\
\hline Pugh RJ, et al. (1979) & 20 & Hematemesis & Gastric ulcer & Bleeding from 3 areas of gastric ulceration \\
\hline Chhabra RS, et al. $(1994)^{4)}$ & 16,24 & Hematochezia & Salmonella infection & Not done \\
\hline Kumar D, et al. $(2000)^{5)}$ & $25,27,28$ & Hematochezia & Allergic colitis & Erythematous friable mucosa \\
\hline Present case (2016) & 19 & Hematemesis & Hemophilia B & Diffuse hyperemic gastric mucosa with oozing fundus \\
\hline
\end{tabular}

Abbreviations: GIH, Gastrointestinal hemorrhage; GI, gastrointestinal. 
was achieved. Although the infant was not subjected to open challenge or cow's milk challenge test, and his eosinophil count, and the levels of total Immunoglobulin E (IgE) and allergenspecific IgE were within the normal range, spontaneous GIH did not relapse while breast milk was fed, when the levels of factor IX were approximately $2 \%$.

Severe ICH or ECH that develops during delivery in infants typically raises a suspicion of coagulation factor disorder. However, spontaneous GIH during the neonatal period initially suggests congenital GI malformation or NEC in premature infants. Massive hemorrhage causes disseminated intravascular coagulopathy, which results in increased aPTT. Additional management of prolonged aPTT including administration of FFP may delay the diagnosis of mild coagulation factor deficiency.

In conclusion, coagulation factor deficiency should be considered in infants, particulary in male infants, who present with spontaneous GIH on the first day of life and unexplained pro. longed aPTT. Moreover, even if a patient is diagnosed with hemophilia A or B, other disorders such as GI malformation, NEC, and cow' milk allergy should also be considered, since spontaneous GIH on the first day of life is rarely the first clinical manifestation of hemophilia.

\section{REFERENCES}

1) Reish O, Nachum E, Naor N, Ghoshen J, Merlob P. Hemophilia $B$ in a neonate: unusual early spontaneous gastrointestinal bleeding. Am J Perinatol 1994;11:192-3.

2) Piccin A, O'Marcaigh A, Deiratany S, Mc Mahon C, Smith OP. Severe gastrointestinal haemorrhage, first manifestation of neonatal haemophilia A. Haemophilia 2009;15:17-9.

3) Pugh RJ, Newton RW, Percy M. Fatal bleeding from gastric ulceration during first day of life-possible association with social stress. Arch Dis Child 1979;54:146-8.

4) Chhabra RS, Glaser JH. Salmonella infection presenting as hematochezia on the first day. Pediatrics 1994;94:739-41.

5) Kumar D, Repucci A, Wyatt-Ashmead J, Chelimsky G. Allergic collitis presenting in the first day of life: report of three cases. J Pediatr Gastroenterol Nutr 2000;31:195-7.

6) Richards M, Lissalde GL, Combescure C, Batorova A, Dolan G, Fischer K, et al. Neonatal bleeding in haemophilia: a European cohort study. Br J Haematol 2012;156:374-82.

7) Kulkarni R, Soucie JM, Lusher J, Presley R, Shapiro A, Gill J, et al. Sites of initial bleeding episodes, mode of delivery and age of diagnosis in babies with haemophilia diagnosed before the age of 2 years: a report from The Centers for Disease Control and Prevention's (CDC) Universal Data Collection (UDC) project. Haemophilia 2009;15:1281-90.

8) Baehner RL, Strauss HS. Hemophilia in the first year of life. $N$ Engl J Med 1996;275:24-8.

9) Kliegman RM, Stanton BF, St Geme JW, Schor NF. Nelson text book of pediatrics. 20th ed. Philadelphia: Elsevier Co., 2016:812-3

10) Chalmers EA. Neonatal coagulation problems. Arch Dis Child Fetal Neonatal Ed 2004;89:F475-8.

11) Baujard C, Couyet L, Murat I. Diagnosis and anaesthesia ma nagement of haemophilia during the neonatal period. Paediatr Anaesth 1998;8:245-7.

12) Stonebraker JS, Bolton-Maggs PH, Michael Soucie J, Walkers I, Brooker M. A study of variations in the reported haemophilia B prevalence around the world. Haemophilia 2012;18:e91-4.

13) Conway JH, Hilgartner MW. Initial presentations of pediatric hemophiliacs. Arch Pediatr Adolesc Med 1994;148:589-94.

14) Barkat A, Kabiri M, Zaari Y, Ghazali H, Karboubi L, El khorassani M, et al. Hemophilia in a newborn with an unusual clinical presentation. Arch Pediatr 2009;16:1068-70.

15) Srivastava A, Brewer AK, Mauser-Bunschoten EP, Key NS, Kitchen S, Llinas A, et al. Guidelines for the management of hemophilia. 2013;19:e1-47. 